\title{
Umbilical cord blood and neonatal endothelin-1 levels in preterm newborns with and without respiratory distress syndrome
}

\section{A.C.W. Benjamin, \\ R.C. Silveira \\ and R.S. Procianoy}

Serviço de Neonatologia, Hospital de Clínicas de Porto Alegre e Departamento de Pediatria, Universidade Federal do Rio Grande do Sul, Porto Alegre, RS, Brasil

\section{Correspondence}

R.S. Procianoy

Rua Tobias da Silva, 99/302

90570-020 Porto Alegre, RS

Brasil

Fax: +55-51-3331-2738

E-mail: renatosp@terra.com.br

Research partially supported by the Hospital de Clínicas de

Porto Alegre Research Incentive Fund (FIPE-HCPA, No. 00319)

Received December 8, 2004

Accepted July 4, 2005

\begin{abstract}
Increased pulmonary vascular resistance in preterm newborn infants with respiratory distress syndrome is suggested, and endothelin-1 plays an important role in pulmonary vascular reactivity in newborns. We determined umbilical cord blood and neonatal (second sample) levels of endothelin- 1 in 18 preterm newborns with respiratory distress syndrome who had no clinical or echocardiographic diagnosis of pulmonary hypertension and 22 without respiratory distress syndrome (gestational ages: $31.4 \pm 1.6$ and $29.3 \pm 2.3$ weeks, respectively). Umbilical cord blood and a second blood sample taken 18 to $40 \mathrm{~h}$ after birth were used for endothelin-1 determination by enzyme immunoassay. Median umbilical cord blood endothelin-1 levels were similar in both groups (control: 10.9 and respiratory distress syndrome: $11.4 \mathrm{pg}$ / $\mathrm{mL}$ ) and were significantly higher than in the second sample (control: $1.7 \mathrm{pg} / \mathrm{mL}$ and respiratory distress syndrome: $3.5 \mathrm{pg} / \mathrm{mL}, \mathrm{P}<0.001$ for both groups). Median endothelin-1 levels in the second sample were significantly higher in children with respiratory distress syndrome than in control infants $(\mathrm{P}<0.001)$. There were significant positive correlations between second sample endothelin- 1 and Score for Neonatal Acute Physiology and Perinatal Extension II ( $\mathrm{r}=0.36, \mathrm{P}=0.02)$, and duration of mechanical ventilation $(r=0.64, P=0.02)$. A slower decline of endothelin- 1 from birth to $40 \mathrm{~h}$ of life was observed in newborns with respiratory distress syndrome when compared to controls. A significant correlation between neonatal endothelin-1 levels and some illness-severity signs suggests that endothelin- 1 plays a role in the natural course of respiratory distress syndrome in preterm newborns.
\end{abstract}

\section{Introduction}

Recent studies suggest that there is increased pulmonary vascular resistance in preterm newborn infants with respiratory distress syndrome (RDS). The mechanisms
Key words

- Endothelin-1

- Respiratory distress syndrome

- Prematurity

- Hyaline membrane disease

- Pulmonary hypertension

- SNAPPE II involved, however, are unknown (1-3).

Endothelin (ET) is a peptide of 21 amino acids in chain with two disulfide bonds with three distinct isoforms: ET-1, ET-2, and ET3 (4). ET causes isolated contraction of pulmonary veins, vascular smooth muscle mito- 
genesis, myocardial cell hypertrophy, positive inotropic and chronotropic effects, bronchoconstriction, mucous secretion, cellular proliferation, and inflammatory reactions (511). ET-1 has a potent pulmonary vasoconstrictor effect $(5-8,10-13)$.

Experimental studies have suggested that ET-1 plays an important role in pulmonary vascular reactivity in neonatal RDS $(3,14)$. There is also an elevation of ET-1 in tracheal aspirates from these infants (15). High blood ET-1 levels have also been reported in neonatal sepsis (16), perinatal asphyxia $(17,18)$, congenital diaphragmatic hernia (19), persistent pulmonary hypertension of the newborn (13,20-23), and acute respiratory distress syndrome (ARDS) in children (24).

Our hypothesis is that ET-1 is involved in the pathogenesis of RDS in preterm infants. Therefore, we have measured the levels of ET-1 in umbilical cord blood and 18 to $40 \mathrm{~h}$ after birth in preterm newborns with and without RDS.

\section{Patients and Methods}

The study protocol was approved by the Ethics Committee of Hospital de Clínicas de Porto Alegre and informed written consent was obtained from parents or guardians of the patients.

\section{Study population}

Newborns with a gestational age of 34 weeks or less and a birth weight of $2000 \mathrm{~g}$ or less delivered at the obstetric center of Hospital de Clínicas de Porto Alegre, RS, Brazil, between January 2001 and November 2003 were selected to participate prospectively in the study.

The exclusion criteria were clinical or laboratory evidence of congenital infection, neonatal sepsis, 5-min Apgar score of less than 5, congenital malformation, maternal drug addiction, maternal syphilis, toxoplasmosis, rubella, cytomegalovirus, herpes virus 1 and 2 during pregnancy, HIV-positive mothers, maternal use of opiates or drugs capable of causing respiratory depression in the peripartum period, and use of nitric oxide.

The diagnosis of RDS was based on the presence of respiratory distress in the first 24 $\mathrm{h}$ of life with tachypnea, chest retractions, and expiratory grunting requiring more than $40 \%$ oxygen to keep a hemoglobin saturation of $92 \%$, a chest X-ray study showing a reticulogranular pattern, and a satisfactory response to exogenous surfactant therapy.

Bronchopulmonary dysplasia (BPD) was diagnosed based on the criteria of the NICHD/ NHLBI/ORD Workshop on Bronchopulmonary Dysplasia (25).

Gestational age was assessed by the last menstrual period and first trimester ultrasonogram and confirmed by the method of Ballard et al. (26).

Newborns were classified as small for gestational ages when their birth weights were less than the 10th percentile on the intrauterine growth curve of Alexander et al. (27).

The Score for Neonatal Acute Physiology and Perinatal Extension II (SNAPPE II) was obtained at the end of the first $24 \mathrm{~h}$ for all newborns (28).

\section{Classification of the newborns}

The control group consisted of 22 preterm newborn infants who presented no respiratory manifestations or who required less than $40 \%$ oxygen with a maximal duration of 72 $\mathrm{h}$, and made no use of exogenous surfactant.

The RDS group consisted of 18 preterm infants with RDS as defined above, and no clinical or echocardiographic diagnosis of pulmonary hypertension.

\section{Determination of ET-1 in plasma}

Umbilical venous cord blood was collected at birth from all newborns, and an additional venous blood sample was taken 
when RDS usually becomes worse, between 18 and $40 \mathrm{~h}$ after birth (second sample), for ET-1 measurement. No venous punctures were performed only for the study. The blood samples $(600 \mu \mathrm{L})$ were collected into tubes with EDTA and centrifuged immediately and plasma was frozen at $-70^{\circ} \mathrm{C}$. All samples were tested in duplicate. ET-1 was determined by an enzyme immunoassay (QuantiGlo Human ET-1, R\&D Systems, Inc., Minneapolis, MN, USA). The minimum detectable dose of ET-1 was $0.16 \mathrm{pg} / \mathrm{mL}$, with intra- and interassay coefficients of variation of 2.5 and 5\%, respectively. Readings were carried out in a luminometer.

\section{Statistical analysis}

The sample size necessary was calculated to be 17 newborns in each group to achieve a significance of $5 \%$, a power of $80 \%$ for a difference of $40 \%$ in ET-1 levels between the two groups based on data published previously (17). Data are reported as means $\pm \mathrm{SD}$ or medians and interquartile range (p25-p75). The Student $t$-test and the Mann-Whitney test were employed for parametric and non-parametric data, respectively. Categorical data were analyzed by the chi-square test and Fischer exact test. Spearman's correlation coefficients were calculated for ET-1 and SNAPPE II, and ET-1 and duration of mechanical ventilation.

Since logarithmic functions were used for comparison of ET-1 levels in cord blood and second samples between control and RDS groups, we were able to employ repeated-measures ANOVA adjusted for birth weight, gestational age and Apgar score in the fifth minute of life, and one-way ANOVA for the control and RDS with and without BPD groups. Significance was established at $\mathrm{P}<0.05$.

\section{Results}

Forty newborns were enrolled in the study: 22 in the control group and 18 in RDS group. The two groups were similar in gender, type of birth, proportion of small for gestational age, and mean second sample timing. Newborns in the RDS group were more premature, had a lower birth weight and 5-min Apgar scores, and a higher SNAPPE II than the controls (Table 1). All newborn infants in the RDS group and 15 in the control group had a blood culture performed in the first $24 \mathrm{~h}$ of life. Cultures were negative for both groups. Five patients in the RDS group and none in the control died.

Umbilical venous cord ET-1 levels did not differ between the patients of the two groups. Significantly higher second sample ET-1 concentrations were measured in RDS patients compared to control (Table 2).

Umbilical venous cord ET-1 concentrations were higher than second sample ET-1 levels in both groups $(\mathrm{P}<0.001)$. Repeatedmeasures ANOVA revealed a difference

Table 1. Characteristics of the population studied.

\begin{tabular}{lcc}
\hline & Control group (N =22) & RDS group (N = 18) \\
\hline Gestational age (weeks) & $31.4 \pm 1.6$ & $29.3 \pm 2.3^{*}$ \\
Birth weight (g) & $1580 \pm 276$ & $1065 \pm 220^{*}$ \\
Male/female & $11 / 11$ & $10 / 8$ \\
C-section & $15(68.2 \%)$ & $15(83.3 \%)$ \\
Small for gestational age & $4(18.1 \%)$ & $5(27.7 \%)$ \\
Five-minute Apgar score & $9(8-9)$ & $8(6-9)^{\star *}$ \\
SNAPPE II & $0(0-9)$ & $24(18-37)^{\star *}$ \\
Second sample timing (h) & $29.7 \pm 10.2$ & $30.3 \pm 9.3$ \\
\hline
\end{tabular}

Data are reported as mean $\pm S D$ and median (p25-p75). RDS = respiratory distress syndrome; SNAPPE II = Score for Neonatal Acute Physiology and Perinatal Extension II.

${ }^{*} \mathrm{P}<0.05$ compared to control group (Student $t$-test). ${ }^{\star \star} \mathrm{P}<0.05$ compared to control group (Mann-Whitney test).

Table 2. Umbilical cord and second sample endothelin-1 (ET-1) levels.

\begin{tabular}{lcc}
\hline & Control group $(\mathrm{N}=22)$ & RDS group $(\mathrm{N}=18)$ \\
\hline Umbilical cord ET-1 $(\mathrm{pg} / \mathrm{mL})$ & $10.9(7.4-14.2)$ & $11.4(7.1-17.3)$ \\
Second sample ET-1 $(\mathrm{pg} / \mathrm{mL})$ & $1.7(1.4-2.2)$ & $3.5(2.7-4.9)$
\end{tabular}

Data are reported as median (p25-p75). RDS = respiratory distress syndrome. $\mathrm{P}<0.001$ between umbilical cord blood and second blood sample in both groups (repeated-measures ANOVA). $\mathrm{P}<0.001$ between second sample in both groups (Mann-Whitney test). 
between the two groups $(\mathrm{P}=0.007)$ which was still present after adjusting for gestational age, birth weight, and 5-min Apgar score $(\mathrm{P}=0.015)$.

There was no correlation between umbilical venous cord ET-1 and SNAPPE II. There was a significant positive correlation between second sample ET-1 and SNAPPE II $(r=0.36, P=0.02)$. There were no correlations between umbilical venous cord and second sample ET-1 concentrations and 5min Apgar score $\leq 6$. Duration of mechanical ventilation had a significant positive correlation with second sample ET-1 $(r=0.64, \mathrm{P}$ $=0.02$ ), but not with umbilical venous cord ET-1.

Three patients in the RDS group developed BPD. Umbilical venous cord ET-1 levels did not differ between control, RDS without BPD and RDS with BPD (10.95, 11.2 and $13.8 \mathrm{pg} / \mathrm{mL}$, respectively, $\mathrm{P}=0.964)$. Second sample ET-1 levels did not differ between patients with RDS, without BPD and with BPD (3.7 and $3.9 \mathrm{pg} / \mathrm{mL}$, respectively, $\mathrm{P}=0.93)$. Both had significantly higher ET-1 levels than controls $(\mathrm{P}=0.001$ and $\mathrm{P}=0.05$, respectively).

Umbilical venous cord and second sample ET-1 levels were similar in non-survivor and survivor RDS patients (Table 3).

\section{Discussion}

ET-1, nitric oxide, prostaglandins, bradykinins, and other hormones modulate pulmonary vascular tone in normal fetuses (29-

Table 3. Characteristics of the newborns according to survival.

\begin{tabular}{lcc}
\hline & Non-survivors $(\mathrm{N}=5)$ & Survivors $(\mathrm{N}=13)$ \\
\hline Gestational age (weeks) & $29.4 \pm 1.9$ & $29.3 \pm 2.4$ \\
Birth weight $(\mathrm{g})$ & $922 \pm 275$ & $1119 \pm 177$ \\
Umbilical cord ET-1 $(\mathrm{pg} / \mathrm{mL})$ & $11.7(9.8-20.5)$ & $9.4(5.6-15.8)$ \\
Second sample ET-1 $(\mathrm{pg} / \mathrm{mL})$ & $3.8(2.7-8.5)$ & $3.4(2.6-4.5)$
\end{tabular}

Data are reported as mean \pm SD and median (p25-p75). There were no statistical differences by the Student $t$-test and the Mann-Whitney test between groups.
31). ET-1 acts on pulmonary vessels through ETA receptors present on smooth muscle in the fetal lung and ETB receptors located on the endothelial cells. Binding of ET-1 to ETA results in vasoconstriction, and binding to ETB results in vasodilatation $(29,30)$. High umbilical cord ET-1 levels are related to adaptation to extrauterine life (12). Therefore, it is not surprising that RDS and control newborns have similar umbilical cord ET-1 levels.

ET-1 concentration in cord blood is much higher than in maternal blood, and levels are similar in both umbilical artery and vein, suggesting that there is no active transport across the placenta (32).

Term newborn infants have high ET-1 levels in the first hours, which decrease progressively (29). Hypoxia, pulmonary diseases, malformations, or even prematurity may cause a derangement in the balance of vasoconstrictor and vasodilator mediators.

Experimental models have suggested that ET-1 plays a role in pulmonary vascular reactivity in preterm newborns with RDS $(3,14)$. There are few studies measuring ET1 by radioimmunoassay with a very small number of human preterm newborns suggesting that ET-1 is elevated in RDS (17, $33,34)$. Our study is important because it was controlled, had a significant sample size calculated statistically, and ET-1 was measured by enzyme immunoassay, differently from the other three reported studies. The study population consisted only of preterm newborn infants, with 5-min Apgar scores equal to or higher than 5 in order to avoid a significant influence of perinatal hypoxic insult on ET-1 levels. Our results confirm that preterm newborn infants with RDS have high ET-1 levels 18 to $40 \mathrm{~h}$ after birth.

We show high ET-1 levels in preterm newborns with RDS and no clinical or echocardiographic diagnosis of pulmonary hypertension. Besides its vasoconstrictor effect, ET-1 has mitogenic and inflammatory actions that, in conjunction with other vaso- 
active and inflammatory mediators, cause increased pulmonary vascular resistance, vascular congestion, pulmonary hemorrhage, and endothelium injury (10).

Increased secretion and decreased clearance by lung are the mechanisms suggested for high ET-1 levels in newborns with RDS. Hypoxia can induce an ET-1 surge in fetuses (35). Preterm infants with RDS very often suffer from periods of hypoxia during the course of the disease that may stimulate ET1 production. The lungs are responsible for clearance of $90 \%$ of circulating ET-1 (11). There is no study about ET- 1 clearance in neonatal RDS; however, it has been shown that ET-1 clearance is decreased in adults with ARDS (5), and it is a possible mechanism in preterm newborn infants with RDS.

A slower decline of ET-1 from birth to 40 $\mathrm{h}$ of life in newborns with RDS than in controls, and a significant correlation between neonatal ET-1 levels and some illness-severity signs - duration of mechanical ventilation and SNAPPE II - suggest that ET-1 plays a role in the natural course of RDS in preterm newborns. Niu et al. (36) demonstrated high ET-1 levels in tracheal aspirates from newborns that progressed to BPD. High plasma ET-1 levels are associated with elevated mortality in children with ARDS (24). We did not observe an associa- tion between high plasma ET-1 levels and progression to BPD or increased mortality. This distinction may require a study with larger number of patients. According to our objective, the sample size was calculated to evaluate the difference in ET-1 levels of newborns with and without RDS.

In conclusion, our newborn infants with and without RDS had similar umbilical cord ET-1 levels, whereas ET-1 levels were higher in RDS than in control newborns 18 to $40 \mathrm{~h}$ after birth. The increased vascular resistance in RDS may be related to high ET-1 levels, justifying the use of nitric oxide and recommending future studies of new therapeutic modalities, such as ETA blockers in preterm newborns with RDS.

\section{Acknowledgments}

The authors thank Dr. Winston W. Benjamin, Hospital de Clínicas de Porto Alegre (HCPA), for help with data collection, Prof. Dr. Mario Wagner, Universidade Federal do Rio Grande do Sul (UFRGS) and HCPA, for assistance with the statistical analysis, Prof. Dr. Emer S. Ferro, Biomedical Science Institute, University of São Paulo (USP), for assistance with the laboratory analysis of ET-1, and Prof. Isaura Riedl for revising the English text.

\section{References}

1. Skinner JR, Boys RJ, Hunter S et al. (1992). Pulmonary and systemic arterial pressure in hyaline membrane disease. Archives of Diseases in Childhood, 67: 355-373.

2. Walther FJ, Benders MJ \& Leighton JO (1992). Persistent pulmonary hypertension in premature neonates with severe respiratory distress syndrome. Pediatrics, 90: 899-904.

3. Vroomen M, Cardozo RHL, Steendijk P et al. (2001). Endothelin-1 plasma concentration increases in the early phase of pulmonary hypertension development during respiratory distress syndrome: a study in newborn lambs. Early Human Development, 63: 9-21.

4. Yanagisawa M, Kurihara $\mathrm{H}$, Kimura $\mathrm{S}$ et al. (1988). A novel potent vasoconstrictor peptide produced by vascular endothelial cells. $\mathrm{Na}$ ture, 332: 411-415.

5. Lerman A, Hildebrand FL, Margulies KB et al. (1990). Endothelin: a new cardiovascular regulatory peptide. Mayo Clinic Proceedings,
65: $1441-1455$.

6. Druml W, Steltzer H, Waldhäusl W et al. (1993). Endothelin-1 in adult respiratory distress syndrome. American Review of Respiratory Diseases, 148: 1169-1173.

7. Levin ER (1995). Endothelins. New England Journal of Medicine, 333: $356-363$.

8. Michael JR \& Markewitz BA (1996). Endothelins and the lung. American Journal of Respiratory and Critical Care Medicine, 154: 555-581.

9. Schears GJ \& Costarino AT (1999). Complexity of inflammatory mediators in acute respiratory distress syndrome (ARDS). Journal of Pediatrics, 135: 144-146.

10. Fagan KA, McMurtry IF \& Rodman DM (2001). Role of endothelin-1 in lung disease. Respiratory Research, 2: 90-101.

11. Goraca A (2002). New views on the role of endothelins. Endocrine 
Regulations, 36: 161-167.

12. Perreault T \& Coceani F (2003). Endothelin in the perinatal circulation. Canadian Journal of Physiology and Pharmacology, 81: 644653.

13. Michel RP, Langleben D \& Dupuis J (2003). The endothelin system in pulmonary hypertension. Canadian Journal of Physiology and Pharmacology, 81: 543-554.

14. Andersson S, Merritt A, Orpana A et al. (1997). High endothelin-1 in the airways of preterm infants is associated with less severe respiratory distress during the early postnatal period. Pediatrics, 99: 545547.

15. Ivy DD, Parker TA, Kinsella JP et al. (1998). Endothelin A receptor blockade decreases pulmonary vascular resistance in premature lambs with hyaline membrane disease. Pediatric Research, 44: 175180.

16. Figueras-Aloy J, Gómez L, Rodríguez-Miguélez JM et al. (2003). Plasma nitrite/nitrate and endothelin-1 concentrations in neonatal sepsis. Acta Paediatrica, 92: 582-587.

17. Kojima T, Isozaki-Fukuda Y, Takedatsu M et al. (1992). Plasma endothelin-1 like immunoreactivy levels in neonates. European Journal of Pediatrics, 151: 913-915.

18. Laforgia N, Difonzo I, Altomare M et al. (2001). Cord blood endothelin-1 and perinatal asphyxia. Acta Paediatrica, 90: 351-352.

19. Kobayashi H \& Puri $P$ (1994). Plasma endothelin levels in congenital diaphragmatic hernia. Journal of Pediatric Surgery, 29: 1258-1261.

20. Kumar P, Kazzi NJ \& Shankaran S (1996). Plasma immunoreactive endothelin-1 concentrations in infants with persistent pulmonary hypertension of the newborn. American Journal of Perinatology, 13: 335-341.

21. Fineman JR, Wong J, Mikhailov T et al. (1999). Altered endothelial function in lambs with pulmonary hypertension and acute lung injury. Pediatric Pulmonology, 27: 147-156.

22. Endo A, Ayusawa M, Minato $M$ et al. (2001). Endogenous nitric oxide and endothelin-1 in persistent pulmonary hypertension of the newborn. European Journal of Pediatrics, 160: 217-222.

23. Truog WE, Pallotto E, Clark $P$ et al. (2002). Interaction of endogenous endothelin-1 and inhaled nitric oxide in term and preterm infants. Clinical Science, 103: 294S-297S.

24. Dobyns EL, Eells PL, Griebel JL et al. (1999). Elevated plasma endothelin-1 and cytokine levels in children with severe acute respi- ratory distress syndrome. Journal of Pediatrics, 135: 246-249.

25. Jobe AH \& Bancalari E (2001). NICHD/NHLBI/ORD Workshop Summary on Bronchopulmonary Dysplasia. American Journal of Respiratory and Critical Care Medicine, 163: 1723-1729.

26. Ballard JL, Khoury JC, Wedig K et al. (1991). New Ballard score, expanded to include extremely premature infants. Journal of Pediatrics, 119: 417-423.

27. Alexander GR, Himes JH, Kaufman RB et al. (1996). A United States national reference for fetal growth. Obstetrics and Gynecology, 87: 163-168.

28. Richardson DK, Corcoran JD, Escobar GJ et al. (2001). SNAP-II and SNAPPE-II: Simplified newborn illness severity and mortality risk scores. Journal of Pediatrics, 138: 92-100.

29. Endo A, Ayusawa M, Minato M et al. (2000). Physiologic significance of nitric oxide and endothelin-1 in circulatory adaptation. Pediatric International, 42: 26-30.

30. Tsukahara H, Sekine K, Miura M et al. (2002). Vasoactive and natriuretic mediators in umbilical cord blood: a report of our observation and review of the literature. Early Human Development, 69: 5764.

31. Ziegler JW, Ivy DD, Kinsella JP et al. (1995). The role of nitric oxide, endothelin, and prostaglandins in the transition of the pulmonary circulation. Clinics in Perinatology, 22: 387-403.

32. Kääpä $P$, Kero P, Ekblad H et al. (1994). Plasma endothelin-1 in the neonatal respiratory distress syndrome. Annales Chirurgiae et Gynaecologiae, 83: 110-112.

33. Nakamura T, Kasai K, Konuma S et al. (1990). Immunoreactive endothelin concentrations in maternal and fetal blood. Life Sciences, 46: 1045-1050.

34. Malamitsi-Puchner A, Economou E, Esfstathopoulos T et al. (1995). Endothelin1-21 plasma concentrations on days 1 and 4 of life in healthy and ill preterm neonates. Biology of the Neonate, 67: 317321.

35. Hashiguchi K, Takagi K, Nakabayashi M et al. (1991). Relationship between fetal hypoxia and endothelin-1 in fetal circulation. Journal of Cardiovascular Pharmacology, 17: S509-S510.

36. Niu JO, Munshi UK, Siddiq MM et al. (1998). Early increase in endothelin-1 in tracheal aspirates of preterm infants: correlation with bronchopulmonary dysplasia. Journal of Pediatrics, 132: 965-970. 